\title{
Research of Intelligent Gas Detecting System for Coal Mine
}

\author{
Chen Hui \\ School of Mechanical and Electrical Engineering, \\ East China Jiaotong University, 330013, Nanchang, China \\ Tel.: 0791-7046122 \\ chenhui@ecjtu.jx.cn
}

\begin{abstract}
According to statistic data of China in recent years, gas explosion accounted for above $70 \%$ in all coal mine accidents. Frequent gas explosion accidents have caused great losses of lives and property. Therefore gas detection and monitoring system is needed to serve as a safety device in coal production. In this paper, an intelligent gas detecting system is designed. This detection instrument adopts SCM AT89S52 as its control hardcore and uses catalytic combustion type gas sensor element MC112 as the sensor for gas (CH4) detecting. The main functions of this system are as follows: monitoring the real-time concentration of $\mathrm{CH} 4$ and displaying the concentration value; emitting sound and light alarm signals if the $\mathrm{CH} 4$ concentration value is beyond the alarm value inputted by keyboard panel; using serial communication port to transmit data to the host computer above ground. The software debugging and hardware simulating of the system above are also implemented at the same time.
\end{abstract}

Keywords: Data collection, Sensor, Coal mine, Serial communication, SCM.

\section{Introduction}

As the most important source of energy in China, Coal consumption is about $70 \%$ of all the energy consumption [1,2]. However, coal mine accident happened frequently in China, lots of people suffered from these disasters. Among all the accident, gas leakage lead to gas explosion is the main reason of these accidents [3,4]. So, it's significantly important to develop gas monitoring safety system in coal production enterprises. In this paper, a gas detection and monitoring system is presented, its main functions including : Real-time monitoring gas concentration, transmitting dynamic safety operation parameters underground coal mine, automatic warning about danger before accident happens and providing useful information on rescuing and evacuating people or equipment to decision makers.

\section{Overall Design of Gas Detecting System}

Gas detecting system should meet some specific needs: it can monitoring combustible gas concentration underground coal mine, warning against over standard gas concentration and transmitting real time data to host computer above ground $[5,6]$. The gas 
detecting system in this paper adopts single-chip microcomputer as control computer; the overall schematic diagram of system is shown in Figure 1. The reason for selecting single-chip microcomputer as a control core is that it possesses advantages of small size, high reliability, low price which made it very suitable to be used in industries of intelligent instrument and real time control field [7].

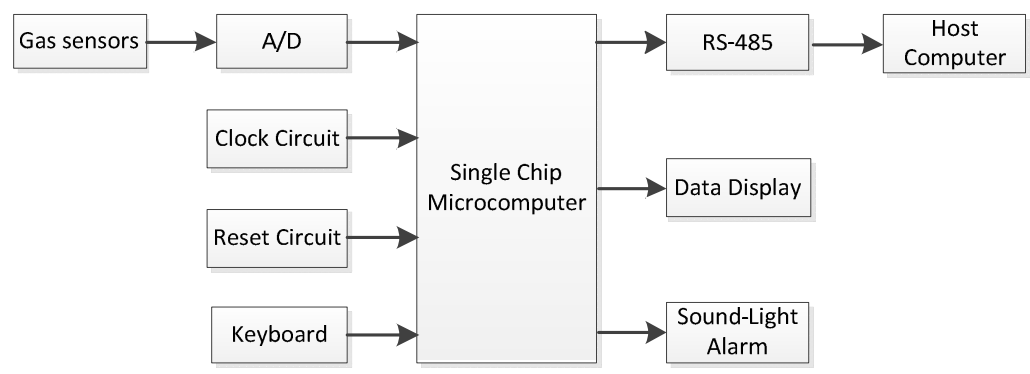

Fig. 1. Schematic diagram of gas detection system

The operating interface of system is shown in Figure 2. Number at upper right corner shows the default or user-defined gas concentration value, number at upper left corner shows detected gas concentration value. One alarm lamp is equipped. All functions are controlled by keys arranged on the control panel, including POWER key, RESET key, DATA COLLECTION key. Other keys including ten number keys, ADJUST VALUE key and ENTER key are used to change threshold values.

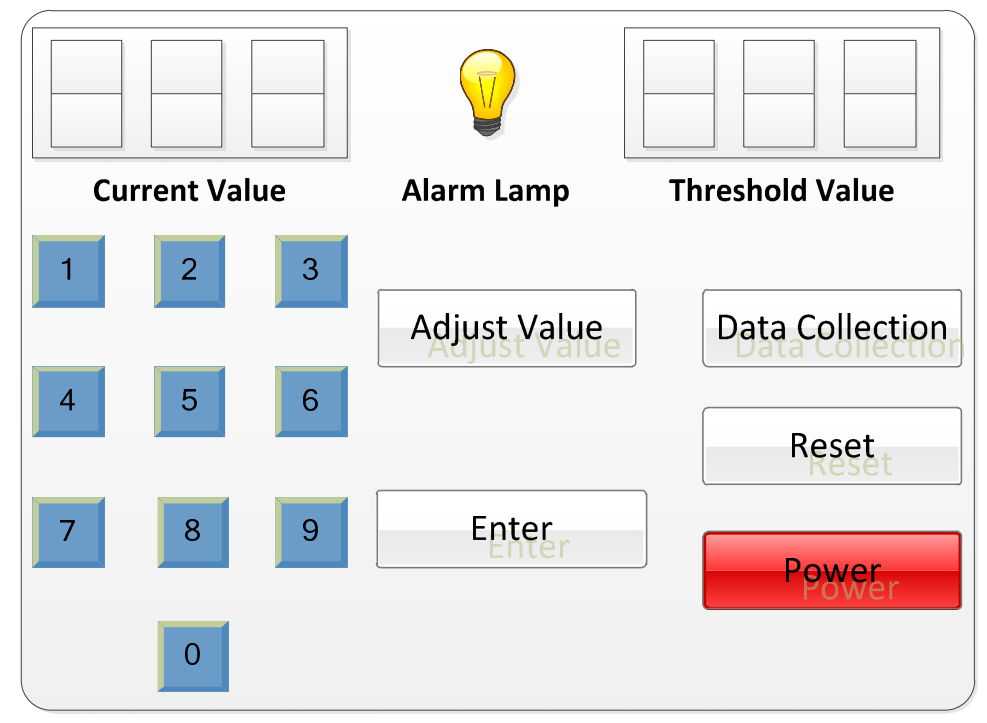

Fig. 2. Operation interface diagram of system 
Basic operating procedures are as follows:

- Firstly press POWER key, the system initialized.

- Press DATA COLLECTION key, LED at upper right corner displays the threshold value 1.00 ;

- User can customized threshold value by press ADJUST VALUE key and ten number keys, then press ENTER to confirm the change.

- System starts to detect gas concentration and display these parameters on upper left LED area, at meantime transmit real-time data by RS-485 to host computer above ground.

\section{Hardware System Design of Gas Detection System}

The Hardware architecture of system mainly including main control unit, sensors and signal amplifier circuit, A/D converter module, sound-light alarming circuit, keyboard and display module, serial-communication module.

\subsection{Main Control Unit}

Featured by high integration level, small size and low prices, Single chip microcomputer has been widely used in a broad range of industrial applications including process controlling, data collection, electromechanical integration, intelligent instrument, household appliances and network technology, and significantly improved the degree of technology and automation.

Two factors are taken into account here in chip selecting, first one is anti-interference ability, the poor working conditions and complex operating situations in mine tunnel increase the interferences in SCM application systems, so the SCM must have high
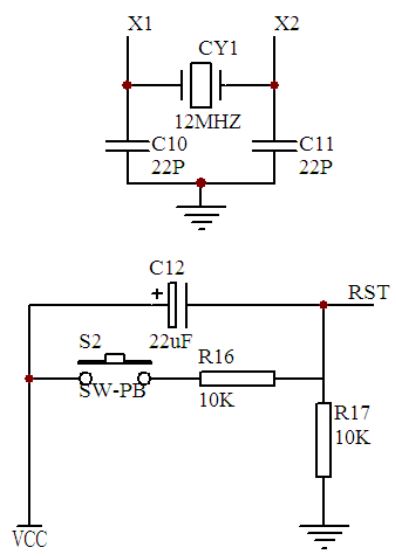

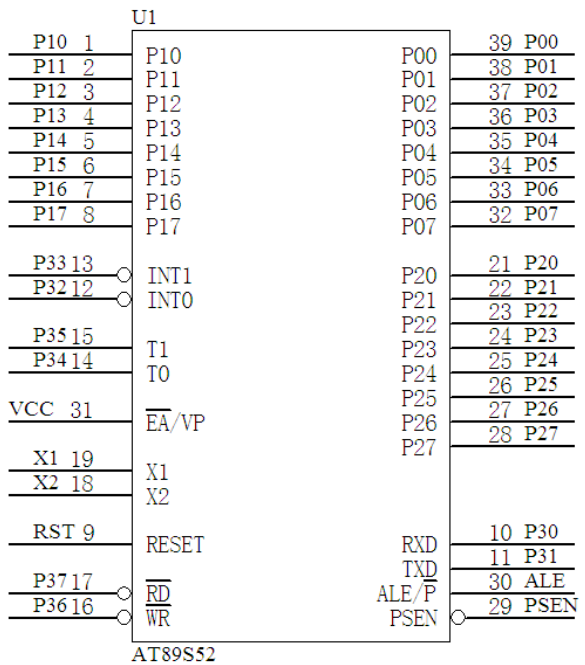

Fig. 3. Main control unit 
resistance to outside interference; second one is the performance-price ratio of the SCM. Considering the aforementioned factors, we adopted the AT89S52 developed by ATMEL as main control unit, and the final scheme of main control circuit consists of AT89S52, timer and reset circuit [8,9]. As shown in figure 3.

\subsection{Sensors and Signal Amplifying Circuit}

\subsubsection{Sensor Selection}

A crucial issue in gas detecting system design is how to select gas sensors. Common gas sensors are metal oxide semiconductor such as tin oxide, zin coxide, titanium oxide and aluminum oxide. Problems encountered with these sensors are lack of flexibility, poor response times and operated at elevated temperature [10]. A new method of ch4 detecting based on infrared techniques was presented in recent years, but it is still in progress and much work should be done before it can be applied to solve the practice problems [11].
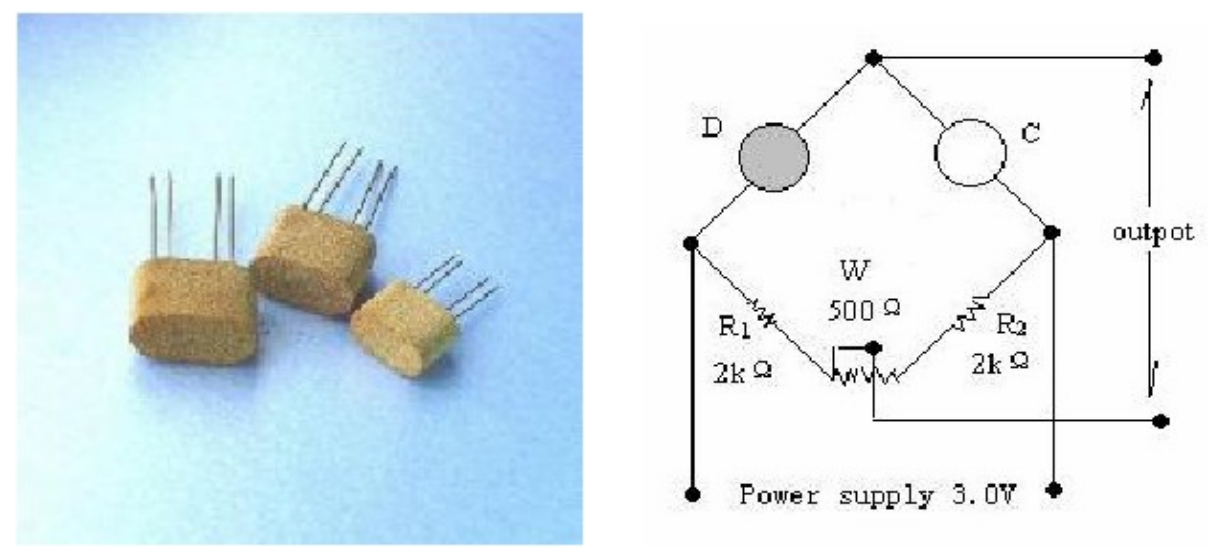

Fig. 4. Outside view and internal circuit of MC112

This system adopted catalytic combustion type gas sensor MC112 developed by SUNSTAR group to measure the gas (ch4) concentration. Figure 4 shows the outside view and internal circuit of $\mathrm{MC112}$, table 1 lists the main technology parameters of MC112. MC112 gas detector exploits catalytic combustion principle; the two-arm bridge is comprised of measure and compensate components pairs. When it is exposed to combustible gases, measure components resistance RS increased and transmit output voltage parameter through measuring bridge, the voltage parameter is directly proportional to the gas concentration value. The compensate component works as temperature compensation and reference. Main features of MC112 include good repeatability, work stably, reliability, linear output voltage, and quick response. The mine safety rules stated that if methane gas concentration exceeds $1 \%$, safety system should make an alert, if gas concentration exceeds $2 \%$, all people must evacuate immediately. Since the detecting range of $\mathrm{MC} 112$ for low concentration methane is $0 \%-2 \%$, it is suitable for measuring low concentration methane in the coal mine. 
Table 1. Main technical parameters of MC112

\begin{tabular}{|c|c|c|}
\hline \multicolumn{2}{|c|}{ Rated voltage (V) } & $3.0 \pm 0.1$ \\
\hline \multicolumn{2}{|c|}{ Rated current (mA) } & @ 100 \\
\hline \multirow{3}{*}{$\begin{array}{l}\text { Sensitivity } \\
(\mathrm{mV})\end{array}$} & $1 \% \mathrm{CH} 4$ & $>14$ \\
\hline & 1\%Butane & $>30$ \\
\hline & 1\%Hydrogen & $>24$ \\
\hline \multicolumn{2}{|c|}{ Linearity $(\%)$} & $0 \sim 5$ \\
\hline \multicolumn{2}{|c|}{ Response time (90\%) } & Less than $10 \mathrm{sec}$. \\
\hline \multicolumn{2}{|c|}{ Renewal time $(90 \%)$} & Less than $30 \mathrm{sec}$. \\
\hline \multicolumn{2}{|c|}{ Application environment } & $-20^{\circ} \mathrm{C} \sim+60^{\circ} \mathrm{C}<95 \% \mathrm{RH}$ \\
\hline \multicolumn{2}{|c|}{ Storage environment } & $-30^{\circ} \mathrm{C} \sim+80^{\circ} \mathrm{C}<95 \% \mathrm{RH}$ \\
\hline \multicolumn{2}{|c|}{ Size } & $10 \times 14 \times 18$ \\
\hline
\end{tabular}

\subsubsection{Signal Amplifier Circuit}

It is necessary to amplify the weak electrical signal detected by MC112 (1\% gas concentration fluctuation will result in 16mv voltage change). The system adopted AD623 developed by AD Company as the high performance instrumentation amplifier. It has many merits: (1) rail-to-rail voltage output with $3-12 v$ single supply (2) easy to modify signal gain though an external resistor, it will be act as a unit gain without external resistor and signal gain can reach to 1000 with an external resistor; (3)low power consumption, large-scale operation voltage, good linearity, good thermal stability and high reliability. The schematic diagram of signal amplifier circuit is shown in figure 5 .

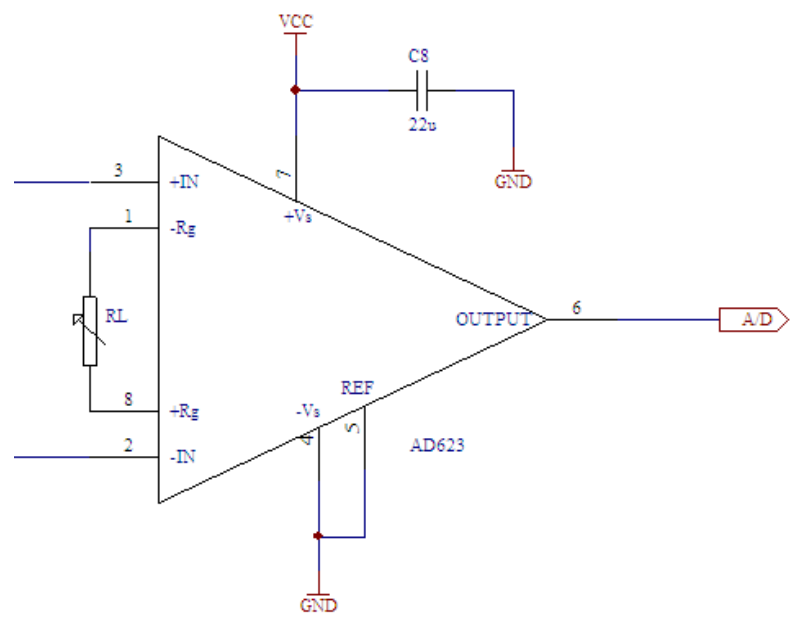

Fig. 5. Signal amplifying circuit 


\subsection{A/D Converter Module}

As shown in Figure 6, this module consists of multiplexer CD4051, sampling holder LF389, A/D converter AD574A[12] and parallel I/O chip 8255A. As a core part, AD574A is a 12-bit successive-approximation A/D converter chip with three-state buffer, its conversion time is about $25 \mu$ s. AD574A can directly connected to AT89S52 without additional interface logic circuit, with internal high accuracy reference power supply and clock circuit, AD574A can operate normally without external clock source and reference power supply.

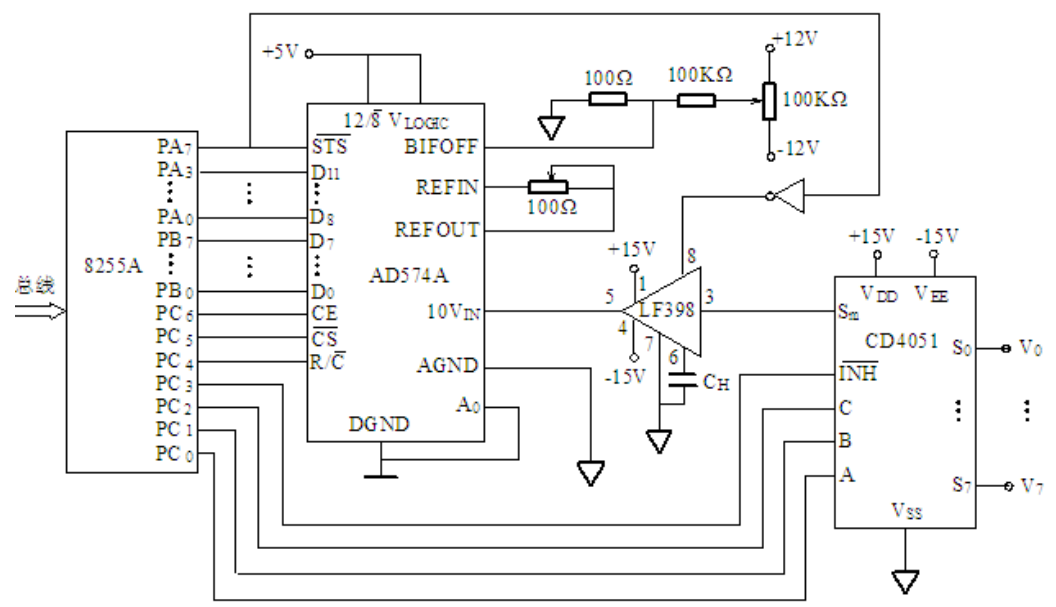

Fig. 6. A/D converter module

\subsection{Other Modules}

\subsubsection{Digital Display Module}

Traditional LCD module is unsuitable in this system because the working environment mainly lies deep in dark coal mine tunnel. LED with soft light should be the alternative. It is suitable for the adverse circumstances under coal mine features by damp-proof, excellence temperature characteristics and long distance visual effects. In this system, a 6-bit LED is adopted to dynamically display the ch4 gas concentration value, with the segment port and bit port connected with PA port and PB port of 8155 (1) separately. The schematic diagram of digital displaying circuit is shown in figure 7 . 


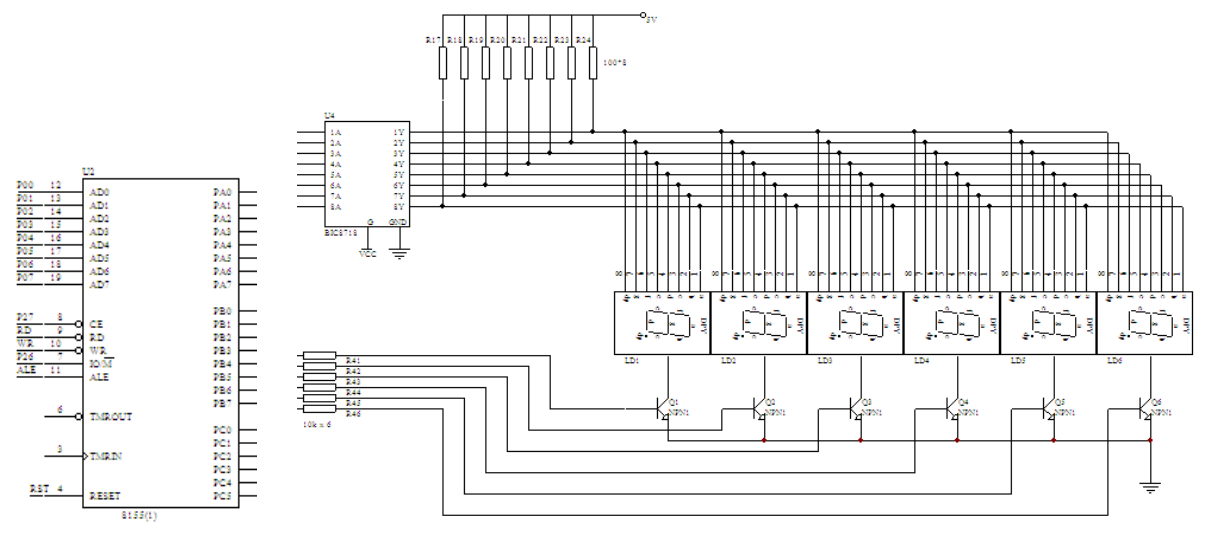

Fig. 7. Digital displaying circuit

\subsubsection{Keyboard Input Module}

In keyboard input module, we arranged 13 keys including 10 number keys and "Data collection" key, "Enter" key, "reset" key. Adopted opposite direction connect method, PB port and PC port of 8155(2) connected to keyboard's row circuit and column circuit respectively. The keyboard input module circuit is shown in Figure 8.

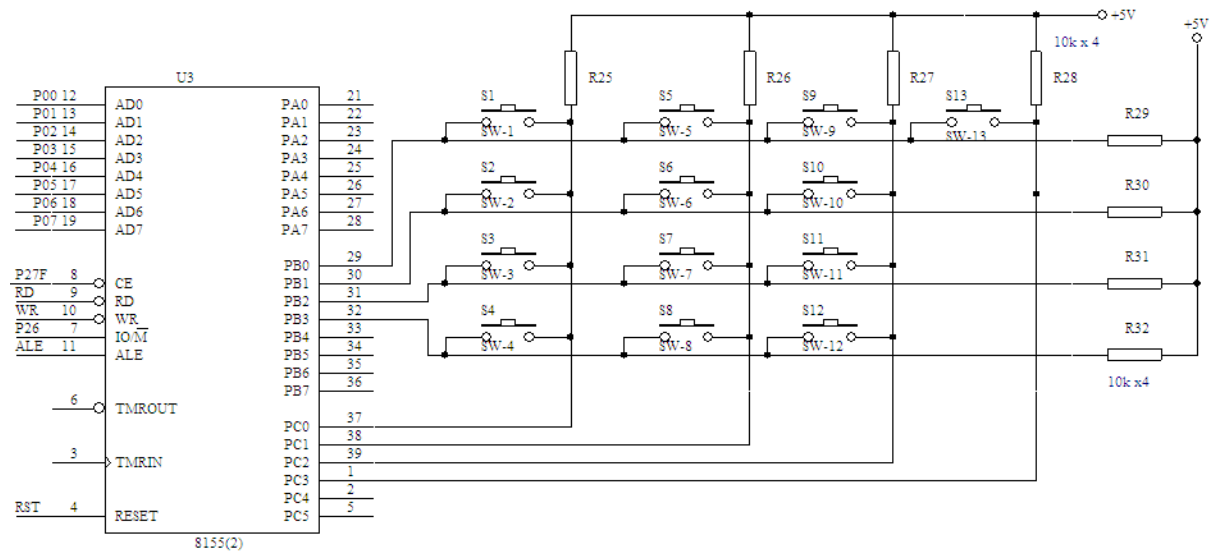

Fig. 8. Keyboard Module Circuit

\subsubsection{Serial Communications and Sound-Light Alarming Units}

The serial communications module is shown at the left part in Figure 9, signal of microcontroller is transmitted to host computer above ground by RS-485, and MAX485 is used to convert the voltage. RS-485 is a multi-point two-way half-duplex communication link based on single balanced-wire circuit featured by high noise suppression, high transfer rate, long distance transmission and Wide common-mode range, its 
maximum transfer rate reaches to $10 \mathrm{Mbps}$, maximum cable distance reaches to $1200 \mathrm{~m}[13,14]$.

The sound-light alarming unit is shown at the right part in Figure 9. As shown in this figure, P21 and P10 of AT89S52 will take control of sound-light alarming unit when the test value of $\mathrm{CH} 4$ gas concentration exceeds the preset value.
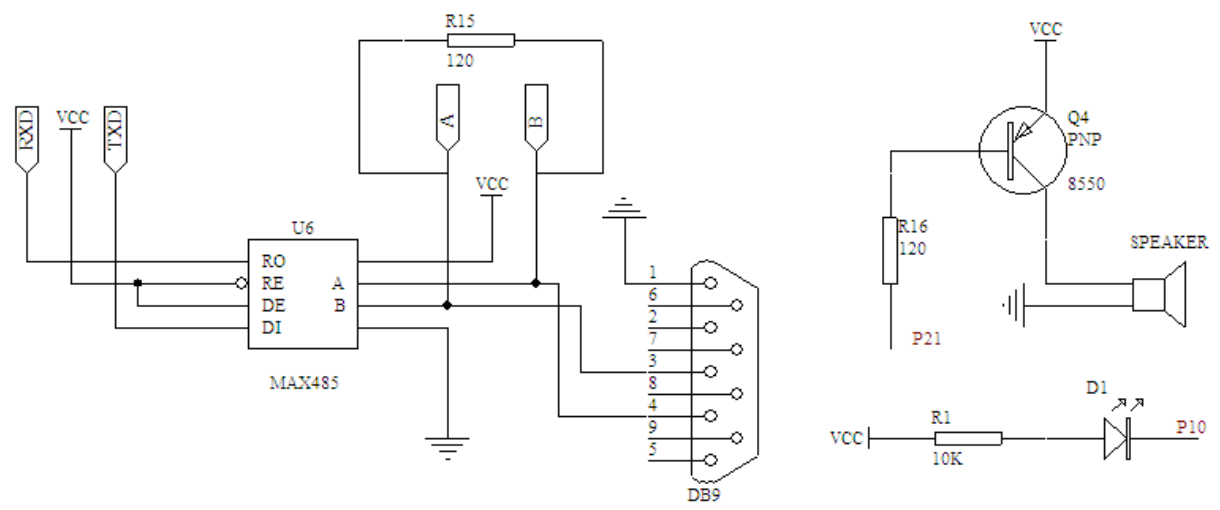

Fig. 9. Serial Communications and Sound-Light alarming units

\section{Software Design of Control System}

The primary functions of the software control system including system initializing, threshold value setting, methane gas concentration data collecting and displaying, serial communications etc. To achieve the above functions, we developed serial programs using 51 serials microcontroller assemble program language including main program, keyboard scanning program, A/D converter program, alarming program, serial communications program, data display program, system alarming diagnosis program, double-byte multiply program, triple-byte to binary-coded-decimal program and watching dog program.

The system is comprised of many modules, Owing to limited space we introduce main program only. The flowchart of main program is shown in Figure 10. Firstly, main program initializing single chip microcomputer's registers and I/O ports, then scanning keyboard to see if the data collection key is pressed, if no, keep scanning keyboard until data collection key is pressed. When the collection key is pressed down, default threshold value 1.00 is shown on the panel, if user wants to reset threshold value, just press the ADJUST VALUE key to set a new value, and press ENTER key to finish this step. When ENTER key is pressed, system start the operating of data collection and A/D conversion, then transmit the converted data into binary format by calling a subprogram of double-byte multiply. We need three storage units to hold these data because they are 24 bits data in binary format. Next, system will transmit these binary format data into binary-coded-decimal format by calling a subprogram of triple-byte to binary-coded-decimal. In the last step, comparing the value with pre-set threshold value to decide if the system should send an alarm signal. In the meantime, 


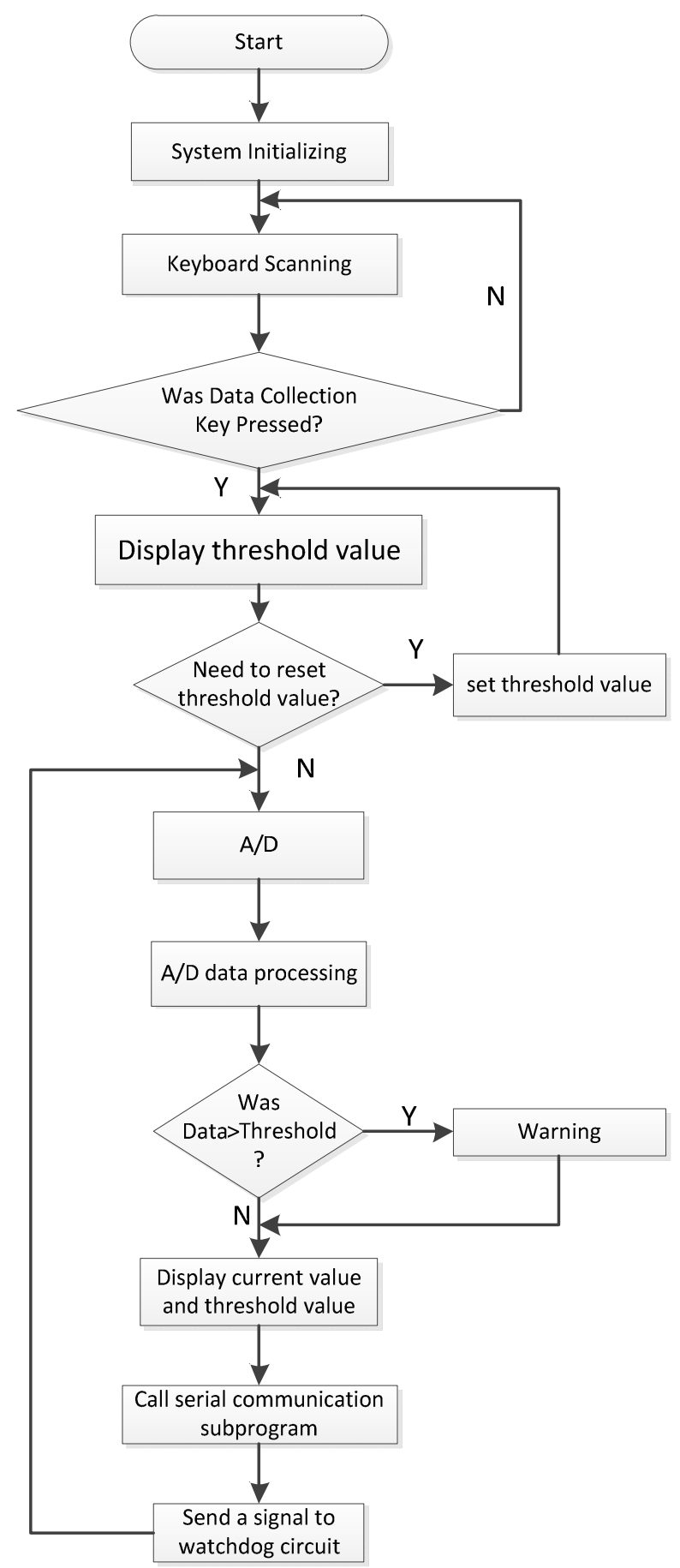

Fig. 10. Flowchart of the main program 
these data will be sending to host computer above ground through RS-485 serial communications unit. Still, the system will send a positive pulse to reset the watchdog timer every $1.6 \mathrm{sec}$. the Crystal Oscillator frequency of the SCM adopted in this system is $12 \mathrm{MHZ}$, with timer/counter TO, working in mode 1 (16bit timer/counter), its maximal timing interval is about $66 \mathrm{~ms}$, so the system will send a feeding dog signal to watch dog circuit every $66 \mathrm{~ms}$.

\section{Conclusions}

In this study, an intelligent gas detecting system is presented. It can be used to real-time monitoring the methane gas concentration underground coal mine. The measuring scope of this system range from zero to 2 percent, the sensitivity of the sensor reach to 0.01 percent. It is equipped with the quick speed and high performance 12-bit A/D converter, the operating environment temperature ranged from $-20^{\circ} \mathrm{C} \sim+70^{\circ} \mathrm{C}$. Still this system features with high reliability, easy to operate, high performance-price ratio. In this paper, the total plan and software and hardware design of a gas detecting system are presented, by using Proteus to test hardware circuit and using Keil to test assemble language source program, the simulation test result shows this system is of high accuracy, quick response and is feasible.

\section{References}

1. Li, Y.H.: Analysis on relationship between economic growth and coal consumption. Economic Tribune 458, 52-53 (2009)

2. Luo, Z.: Optimum utilization of coal resources in western region of China. China Mining Magazine 10(1), 36-39 (2001)

3. Yu, B.F.: Handbook of Coal Mine Gas Disaster Prevention and Utilization. China Coal Industry Publishing House (2005)

4. Zhou, J.M.: Causes for 1.25 Extremely Large Methane Explosion in Gengcun Coal Mine and the Preventive Measures. Safety in Coal Mines 32(3), 32-33 (2001)

5. Wang, K., Hao, N.: Conception of Coal Mine Safety Comprehensive Early Warning System. Safety in Coal Mines 39(11), 103-105 (2008)

6. Yan, Y.G., Zhang, L.: Design of Portable Methane Detection Alarm. Alarm. Safety in Coal Mines 39(9), 32-33 (2008)

7. Yu, Y.Q.: Applications of Single-Chip Microcomputer used in the Control System. Publishing House of Electronics Industry (2003)

8. Sun, Y.C., et al.: New Type AT89S52 Serial Single-Chip Microcomputer and Its Application. Tshinghua University Press (2004)

9. Wang, X.Z.: Theory of AT89 serials Single Chip Microcomputer and Interface Technology. Publishing House of Beihang University (2004)

10. Faizah, M.Y.: Room temperature multi gas detection using carbon nanotubes. European Journal of Scientific Research 35(1), 142-149 (2009)

11. Li, W.J., Hu, Y., Li, T.: Detecting System of Methane Based on Infrared Technology. Safety in Coal Mines 39(11), 63-66 (2008) 
12. Zhang, Z.J.: Application of AD574 in Data Acquisition. International Electronic Elements (6), 55-56 (2003)

13. Xie, R.H.: Complete Collection of Serial Communication Technology. Tsinghua University Press (2003)

14. Castro, M., Sebastian, R., Yeves, F., et al.: Well-known serial buses for distributed control of backup power plants RS-485 versus controller area network(CAN)solutions. Industrial Electronics Society 3(5-8), 2381-2386 (2002) 